\title{
NOTE \\ GENDER AFFECTS NAMING LATENCIES FOR LIVING AND NONLIVING THINGS: IMPLICATIONS FOR FAMILIARITY
}

\author{
Keith R. Laws \\ (Department of Psychology, London Guildhall University, UK)
}

\begin{abstract}
Recent studies indicate the presence of a gender-by-category interaction in the naming abilities of both Alzheimer's patients and normal subjects (Laiacona, Barbarotto and Capitani, 1998; McKenna and Parry, 1994). In particular, males appear to be better than females at naming nonliving things and females better at naming living things. Similarly, in a recent study of semantic fluency, males retrieved more names of tools than females and females more names of fruit than males (Capitani, Laiacona and Barbarotto, 1999). Such findings have important implications for our understanding of category-specific disorders. The current study examined the naming latencies of normal subjects to pictures of living and nonliving things. We confirm a gender-by category interaction across both subject and item, with females being slower than males to name nonliving things and males slower to name living things. This finding could not be explained by differential difficulty of items or differences in gender-based familiarity ratings.
\end{abstract}

Key words: category-specificity, gender differences, familiarity, reaction time, naming

\section{INTRODUCTION}

That some brain-injured patients show greater difficulty recognising and naming items from certain semantic categories is now well-documented. The majority of cases describe patients who have impaired recognition of 'biological' or living things such as animals, fruit and vegetables, although the reverse dissociation, i.e. worse recognition of nonliving items, has been documented in a few cases (for a review, see Caramazza, 1998).

In this context, it is intriguing that two studies of picture naming have reported genderby-category interactions in Alzheimer's patients and normal subjects (Laiacona, Barbarotto and Capitani, 1998; McKenna and Parry, 1994) - documenting that males are generally better than females at naming nonliving things and females better at naming living things. Similarly, a recent study using the semantic fluency paradigm has found that males are better at retrieving the names of tools and females the names of fruit (Capitani, Laiacona and Barbarotto, 1999). Since the reported gender differences accord with gender-stereotyped notions, one possibility is that this phenomenon reflects gender-related differences in familiarity (see Laiacona et al., 1998). Hence, gender differences in category naming offer potentially critical insights into the organising factors of lexical-semantics and therefore, the disordered processes that support category-specific deficits. Moreover, given the unexpected nature of this finding, it is also important to confirm whether this phenomenon occurs in different paradigms, using different stimuli and different measures. To examine this issue further, the current study measured reaction times in male and female normal subjects when naming pictures of living and nonliving things. Finally, we examined whether any gender naming differences were related to gender differences in familiarity with the visual appearance of the items.

Cortex, (1999) 35, 729-733 


\section{MATERIALS AND MethodS}

\section{Subjects}

Thirty-two normal undergraduate subjects (16 males and 16 females) participated in the naming task. All had normal or corrected-to-normal vision and none had previously seen the pictures.

\section{Stimuli and Procedure}

Sixty-four black and white line drawings were taken from the Snodgrass and Vanderwart corpus (1980). The pictures consisted of 32 living (animals, fruit and vegetables) and 32 nonliving items (vehicles, tools and furniture). Musical instruments and body parts were excluded because of their anomalous status in category disorders. The living and nonliving items were matched across category for: concept familiarity (2.82 vs. 2.97: Mann Whitney $\mathrm{Z}=-0.85, \mathrm{p}=.39$ ); visual complexity (3.21 vs. 3.09: Mann Whitney: $\mathrm{Z}=-0.72, \mathrm{p}=$ .47 ); Kucera and Francis name frequency (9.66 vs. 13.23: Mann Whitney $Z=-1.07, p=$ .28 ); number of syallables (4.44 vs. 4.25: Mann Whitney $\mathrm{Z}=-0.48, \mathrm{p}=.63$ ) and phonemes (1.87 vs. 1.81: Mann Whitney $\mathrm{Z}=-0.15, \mathrm{p}=.88$ ).

The images were presented against a white background on a $30 \mathrm{~cm}$ Apple Macintosh monitor using SuperLab software. Each drawing had a maximum horizontal and vertical extent of $7.5 \mathrm{~cm}$ and was viewed from a distance of $50 \mathrm{~cm}$. The pictures were on-screen until response and followed by a blank white screen for 5 seconds. The order of presentation was randomised for each subject. Voice-onset response times (msecs) were recorded with a free-standing microphone. The subjects were asked to name the pictured item as quickly and accurately as possible.

\section{RESULTS}

Analyses are reported across both subjects $\left(\mathrm{F}_{1}\right)$ and items $\left(\mathrm{F}_{2}\right)$ to confirm the robustness of findings. For example, a significant effect across subjects that fails to reach significance across items may reflect anomalies in the items (i.e. a subsample producing extremely high error rates or response times); similarly the reverse dissociation may reflect the inclusion of anomolous subjects. All ANOVA results are detailed in Table I.

\section{Errors}

There was a significant main effect for category (with more nonliving than living errors: means 4.38 vs. 2.53 ) across subjects, but this was not reliable across items. There were no significant effects for gender or the interaction between category and gender.

TABLE I

ANOVA Results across Subjects and Items (for Errors and Response Times)

\begin{tabular}{lcccc}
\hline & \multicolumn{2}{c}{ Error } & \multicolumn{2}{c}{ Response time } \\
\hline & $\begin{array}{c}\text { Subjects } \\
(\text { d.f. }=1,30)\end{array}$ & $\begin{array}{c}\text { Items } \\
(\text { d.f. }=1,62)\end{array}$ & $\begin{array}{c}\text { Subjects } \\
(\text { d.f. }=1,30)\end{array}$ & $\begin{array}{c}\text { Items } \\
(\text { d.f. }=1,62)\end{array}$ \\
\hline Category & $\mathrm{F}_{1}=15.64, \mathrm{p}<.0001$ & $\mathrm{~F}_{2}=1.46, \mathrm{p}=.23$ & $\mathrm{~F}_{1}=3.54, \mathrm{p}=.07$ & $\mathrm{~F}_{2}=2.03, \mathrm{p}=.16$ \\
Gender & $\mathrm{F}_{1}=1.46, \mathrm{p}=.24$ & $\mathrm{~F}_{2}=2.38, \mathrm{p}=.13$ & $\mathrm{~F}_{1}<1$ & $\mathrm{~F}_{2}=26.86, \mathrm{p}<.0001$ \\
Category & $\mathrm{F}_{1}<1$ & $\mathrm{~F}_{2}=1.17, \mathrm{p}=.28$ & $\mathrm{~F}_{1}=8.24, \mathrm{p}=.007$ & $\mathrm{~F}_{2}=6.51, \mathrm{p}=.013$ \\
by Gender & & & & \\
\hline
\end{tabular}

Note. Only the category-by-gender interaction for response time was significant for analyses by both subject and item. 


\section{Response Times}

Prior to analysis, all response times (RTs) for errors were removed, along with outlying RTs of $2.5+$ standard deviations ( $<1 \%$ of RTs). There was a main effect for gender but only across items; and no main effect for category. By contrast, there was a robust genderby-category interaction that was significant across both participants and items. Male subjects were faster than female subjects to name nonliving things [t $(30)=-2.01, \mathrm{p}=.05$ ]; female subjects named living things faster than male subjects, but this failed to reach significance [t $(30)=1.6, \mathrm{p}=.12]$; and finally, females were faster to name living than nonliving things $[\mathrm{t}(15)=-3.25, \mathrm{p}=.005]$. The gender-by-category interaction was also replicated at the level of individual subjects, with $10 / 16(62.5 \%)$ males being faster to name nonliving than living things and $14 / 16(87.5 \%)$ females being faster to name living than nonliving things $\left(\chi^{2}=8.5, \mathrm{p}=.003\right)$.

\section{Correlations}

Male and female RTs and errors were correlated across living and nonliving items separately. For nonliving things, male and female RTs showed a larger correlation $(r=.77)$ than for living things $(\mathrm{r}=.51)$. For error rates, the correlations were high and similar in size $(r=.77$ and $r=.73$ nonliving and living respectively).

\section{Gender-related Visual Familiarity Ratings}

The standard measure of conceptual familiarity (typically derived from the Snodgrass and Vanderwart norms) is somewhat opaque (see Laws and Neve, 1999): representing the degree to which we think about and come into contact with various items. This quantitative measure emphasises the number of contacts with the items; and as such, may be epiphenomenal to the acquisition of the concept (McKenna and Parry, 1994). Using this measure, McKenna and Parry (1994) failed to find that differences in conceptual familiarity

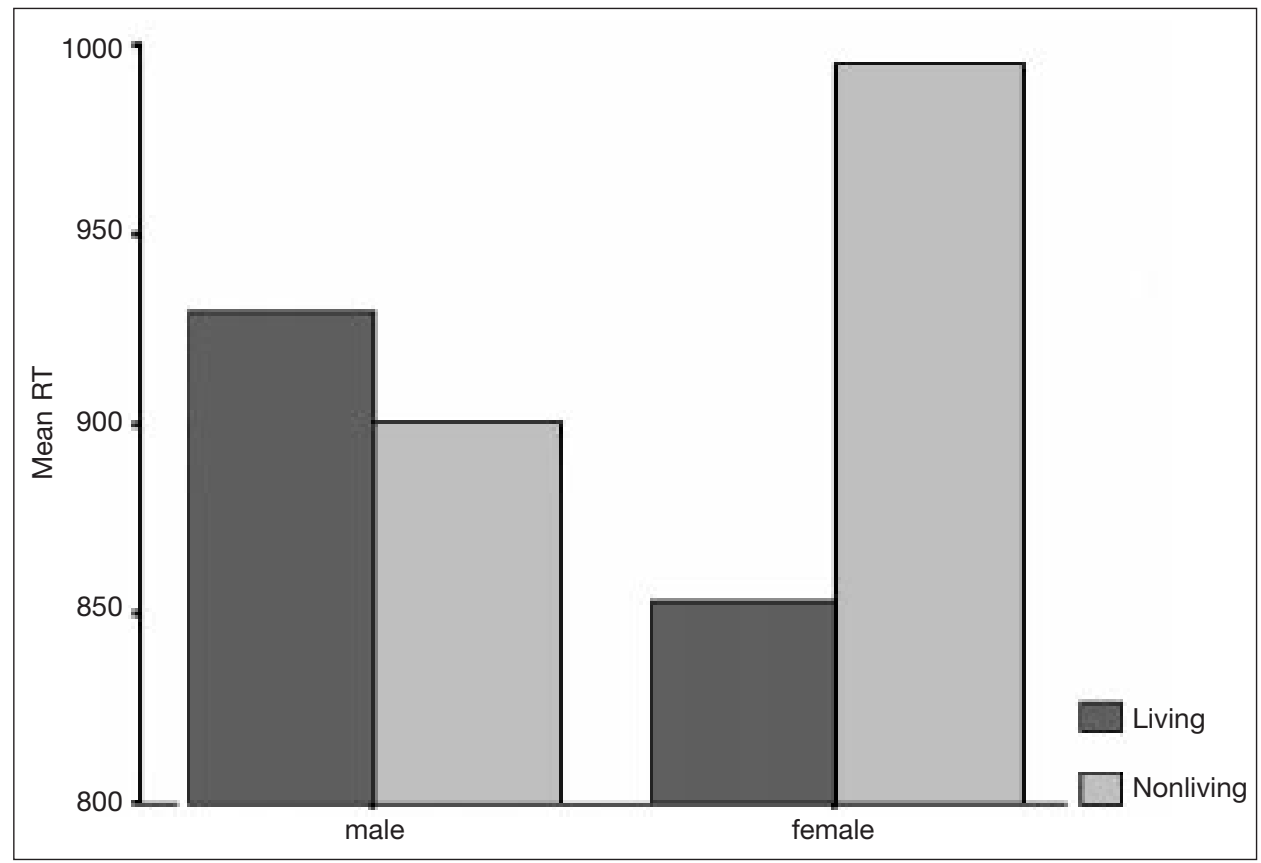

Fig. 1 - Reaction times for male and female subjects for naming living and nonliving items. 
accounted for the worse naming of nonliving things by female subjects (since they rated them as more familiar than male subjects).

More qualitative measures of familiarity have been developed and examined. Laws and Neve (1999) created a measure of visual familiarity - the extent to which subjects are specifically familiar with the visual appearance of items (i.e. what they look like). To examine the influence of this variable in the current study, 20 male and 20 female undergraduates rated the 64 picture names for visual familiarity on a 5 point likert scale (after Snodgrass and Vanderwart, 1980; except that the ratings were made to item names rather than pictures in order to avoid the possibility of misidentification). Again, however, contrary to the 'familiarity' hypothesis, there was a main effect for gender $[\mathrm{F}(1,62)=$ $93.96, \mathrm{p}<.000$ ] with females rating items more highly on visual familiarity than males, but no category effect or gender by category interaction (both $\mathrm{F}<1$ ).

\section{DISCUSSION}

The main finding from this study was a robust gender-by-category interaction for picture naming latencies in normal subjects - this was consistent for analyses both by subject and by item; no other result was significant across both subject and item for either latencies or errors. These findings confirm and expand upon the recent reports of a gender-by-category interaction in the error rates and category fluency of both normal subjects and Alzheimer's patients (Laiacona et al., 1998; McKenna and Parry, 1994; Capitani et al., 1999) and so, cannot simply be rejected as a chance finding. First, this study confirms the presence of a category-by-gender interaction in naming latency; second, it shows that even when there is no comparable interaction for error rates, latency differences emerge; finally, the current data are consistent with the notion that category differences between male and female Alzheimer's patients (see Laiacona et al., 1998) reflect an exaggeration of normal gender differences.

Clearly, this finding cannot be attributed to stimulus attributes. The living and nonliving items were matched for: familiarity, name frequency, visual complexity, number of syallables and phonemes. More critically, any explanation evoking differential item difficulty can be rejected because of the finding of a double dissociation for naming latencies; with males being significantly faster than females to name nonliving items, and females naming living things faster than males (see Figure 1). Moreover, the error data do not support a differential difficulty hypothesis.

Since the naming latency differences accord with gender-stereotyped notions (cf. Laiacona et al., 1998; McKenna and Parry, 1994), the most obvious explanation might be one that attributes such differences to gender-related familiarity differences (see Laiacona et al., 1998). Nevertheless, like McKenna and Parry (1994) who found that conceptual familiarity did not account for gender differences in naming errors, the pattern of visual familiarity ratings given by male and female subjects do not map onto male and female naming latency differences. The confirmatory finding that both living and nonliving things are rated as more familiar by female than male subjects (cf. McKenna and Parry, 1994, for conceptual familiarity) clearly requires further examination.

These results have implications for current notions of familiarity. Two things are clear: first, that existing measures of familiarity fail to tap important gender-related individual differences in naming; and second, that familiarity ratings made by one group of subjects do not map adequately onto the naming responses of another group. It might, of course, be argued that individual familiarity differences are not strongly related to gender-related latency (or error) differences. Another possibility is that, while familiarity (as currently measured) plays a general role in picture naming, it does not sufficiently capture critical differences between groups or even individual subjects. Both ideas, however, seem less likely than the notion that current measures are simply inadequate or restricted in range of predictive use. Even if more accurate measures could be derived, conceptual familiarity certainly has little value as a moderator variable in explaining either category-specific disorders for nonliving things or why normal subjects show better naming of living than nonliving things (Laws and Neve, 1999). This is not to suggest that familiarity per se is 
unimportant, but that it has a limited usefulness in its current conception. Indeed, Laws and Neve (1999) found that visual familiarity was significantly greater for living than nonliving things; and was a good predictor of the tendency for normal subjects to make more nonliving than living naming errors in a speeded presentation paradigm. By contrast, a measure of functional familiarity (the extent to which subjects are familiar with an object's use and/or where it is found) and standard conceptual familiarity were not good predictors. Hence, it may be necessary to think about a variety of familiarities - each being relevant in different contexts, perhaps for different categories of item, different genders or even different subjects. Future studies need to develop novel ways to measure 'familiarities' such that they are capable of incorporating meaningful individual differences.

Acknowledgments. This work was partly supported by a small award from the University of Hertfordshire Psychology Department. Thanks are due to Ann Hagues for helping with the data collection.

\section{REFERENCES}

Capitani, E., Laiacona, M., and Barbarotto, R. Gender affects word retrieval of certain categories in semantic fluency tasks. Cortex, 35: 273-278, 1999.

CARAmazZA, A. The interpretation of semantic category-specific deficits: What do they reveal about the organisation of conceptual knowledge in the brain. Neurocase, 4: 265-272, 1998.

Laiacona, M., BARbarotto, R., and CAPITANI, E. Semantic category dissociations in naming: Is there a gender effect in Alzheimer's disease. Neuropsychologia, 36: 407-419, 1998.

Laws, K.R., and Neve, C. A 'normal' category-specific advantage for naming living things. Neuropsychologia, 37: 1263-1269, 1999.

McKenna, P., and PARRY, R. Category-specificity in the naming of natural and man-made objects: Normative data from adults and children. Neuropsychological Rehabilitation, 4: 255-281, 1994.

SNODGRASS, J.G., and VANDERWART, M. A standardized set of 260 pictures: Norms for name agreement, image agreement, familiarity and visual complexity. Journal of Experimental Psychology: Human Learning and Memory, 6: 174-215, 1980.

Dr. Keith R. Laws, Department of Psychology, London Guildhall University, Calcutta House, Old Castle Street, London E1 7NT, UK. E-mail: Klaws@lgu.ac.uk

(Received 4 June 1999; accepted 26 July 1999) 